\title{
Sequencing Mixed-Model Assembly Line in Electronic Industries Company (EIC)
}

\author{
Asst. Prof. Dr. Sawsan Sabeeh Al-Zubaidy ${ }^{1}$, Asst. Prof. Dr. Mahmoud Abbas Mahmoud ${ }^{1}$, \\ Salam Qaddoori Dawood ${ }^{1}$, Israa Dhiaa Khalaf ${ }^{1}$ \\ Production Engineering and Metallurgy Department/ Industrial Engineering, University Of Technology, Baghdad, Iraq ${ }^{1}$
}

\begin{abstract}
Mixed-model assembly line has great importance because of its variability. This type of assembly line includes two important problems, the first is the mixed-model line balancing problem and the second is the model sequencing problem. The mixed-model line balancing problem is the problem of assigning tasks to stations in a way to get an effective performance measures, and the model sequencing problem is the problem of deciding the sequence in which different models should be released to the same assembly line. This paper focused on sequencing problem that dependent on the results of balancing problem. There are several methods could be used for solving the sequencing problem, we described the Goal chasing 1 method. This method is applied on the assembly plant of Electronic Industries Company (EIC) that assembles different models of automatic changeover (ACH) which is dependent on the results of (MMSLO) program with a heuristic balancing method.
\end{abstract}

Keywords: mixed-model assembly line; Goal chasing 1 method; (MMLSO) program; heuristic methods.

\section{INTRODUCTION}

Mixed-model assembly line means several models of the same basic product are assembled simultaneously in the line. The issues regarding mixed-model assembly line balancing and mixed-model sequencing are strongly related, the result from the line balancing is used as input data to the sequencing. The quality of the sequencing decisions directly depends on the quality of the load balancing. The sequencing problem is the way in which the models feed into the line [1]. To get the best performance as possible now, the models units mix has to be controlled in a way so the balancing is valid, the model sequencing is a short term problem and is often defined per day or per shift time (work time). This shows the difference between the two problems. Where balancing is a rough long term decision that is normally done only once in a while, model sequencing is a subtle short term control

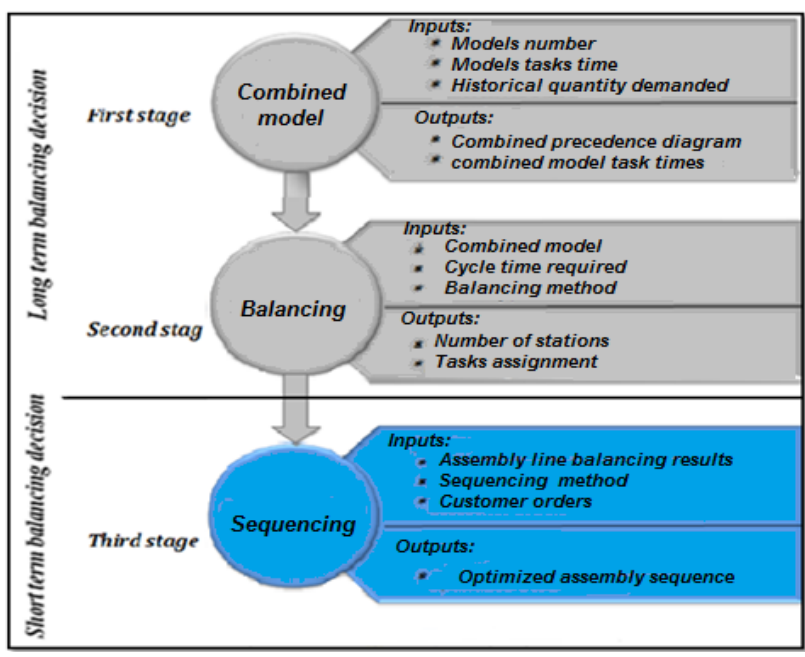

Figure 1: Inputs \& outputs of the shaded third part (sequencing) for the balancing \& sequencing a (MMAL) [2] problem that can help get the best out of a line but requires more precision. The inputs and outputs are shown in figure $1[2]$.

\section{LITRITURE REVIEW}

This section presents different studies published in the last years which start from the oldest to the current years that utilize different methods that overcome the complexity of sequencing problems in assembly lines problems:

Bilal et al. (2010) [3]: In this paper, a simulated annealing approach is developed for the parallel mixed-model assembly line balancing and model sequencing problem which is an extension of the parallel assembly line balancing problem. The proposed approach is illustrated with two numerical examples and its performance is tested on a set of test problems. The computational results show that the proposed approach is very effective.

Alireza \& Shaghayegh (2015) [4]: In this paper, memetic algorithm, genetic algorithm and simulated annealing are applied to a complex sequencing problem. The problem under study concerns about sequencing problem in mixedshop floor environment. The main objective is to minimize the overall make-span of multiple mixed-model assembly lines by finding the best job sequence and allocation.

Alberto et al. (2015) [5]: In this paper, they proposed a hybrid procedure based on bounded dynamic programming assisted by linear programming to solve the mixed-model sequencing problem with workload minimization with serial workstations, free interruption of the operations and with production mix restrictions.

\section{MATHIMATICAL MODEL FOR SEQUENCING METHOD}

The heuristic method (These methods are simple that are used to solve complicated problems. Heuristic methods provide most likely but not optimal solutions, which are 
good enough from a practical point of view) to solve the sequencing problem in this section was presented by Mondon (1983) that shows the sequence of introducing models to the MMAL is different because of the difference in goal of controlling the line; there are two goals of this method which are [6]:

1. Leveling the workloads (total assembly time at every station in the line) between the stations within the line (goal chasing 1)

2. Keeping a fixed rate of usage for every part used by the line (goal chasing 2)

(Goal chasing 1) is the method that will be used in this paper for sequencing the mixed-model line to leveling the workloads among all stations because that all models may not have the same task time at any station in the line. The mathematical model of this method requires many equations such as [7]:

- The average time available at station $m$ to work on each unit launched can be computed as:

$$
\left(\mathrm{T}_{\mathrm{m}} / \mathrm{Q}\right)
$$

Where: $\mathrm{T}_{\mathrm{m}}=$ the time necessary to complete all units of all models at station $\mathrm{m}$ (this value is given from the balancing part).

$\mathrm{R}=$ total quantity demand that is required for all models of product.

- The average time to produce 1 units at station $m$ can be computed as:

$$
\left(\frac{1 . T_{m}}{Q}\right)
$$

Where; $1=$ Launch sequence identification, $1=1,2, \ldots, \mathrm{Q}$.

- Then the model launched at the $1^{\text {th }}$ position in the sequence is the one that

$$
\text { Minimize } \sum_{\mathrm{i}=1}^{\mathrm{p}}\left(\frac{\mathrm{l}_{\mathrm{m}}}{\mathrm{Q}}-\mathrm{X}_{\mathrm{m}, 1-1}-\mathrm{T}_{\mathrm{sm}}\right)^{2}
$$

Where: ; $i=1,2 \ldots$. p.(represent the model number)

$\mathrm{j}=1,2 \ldots \mathrm{k}$ (represent the task number)

$\mathrm{m}=1,2 \ldots . \mathrm{n}$ (represent the station number)

$\mathrm{T}_{\mathrm{sm}}=$ the time necessary to complete all units of model $\mathrm{i}$ at station $\mathrm{m}$. called (the service time)

$\mathrm{X}_{\mathrm{m}, \mathrm{l}-1}=$ necessary assembly time to perform 1-1.units at station $\mathrm{m}$.

\section{PROBLEM DESCRIPTIONS}

The work problems has been applied in the assembly plant of the Electronic Industries Company (EIC) for assemble different models of automatic changeover $(\mathrm{ACH})$. There are three models of Automatic Changeover (ACH). All of these models are assembled manually.

a. Automatic Changeover (80 A) With Timer (model A)

b. Automatic Changeover (30 A) Without Timer (model B)

c. Automatic Changeover (30 A) With Timer (model C)

These models differ from each other in design and in the tasks number and their times, figure 2 shown the models of Automatic Change over.

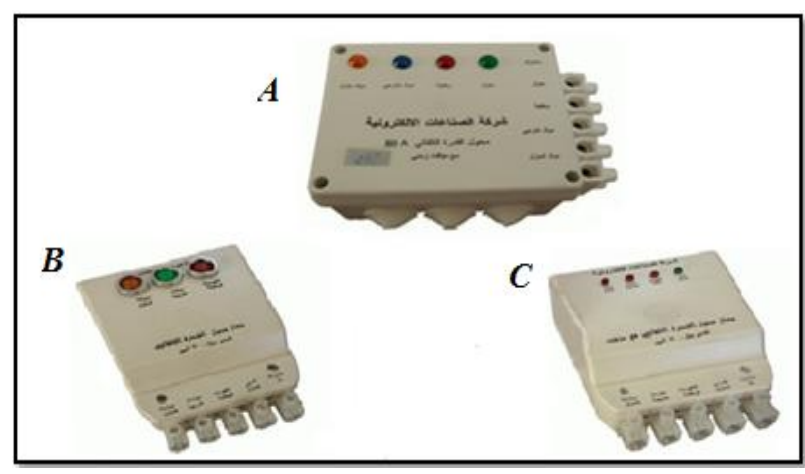

Figure 2: Models of (ACH) [8]

The following figures show the precedence diagram with the task time for each model.

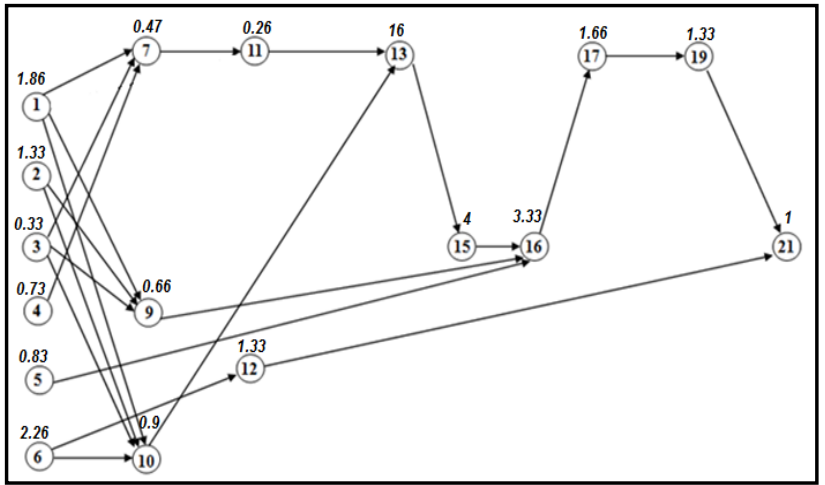

Figure 3: Precedence diagram of model A

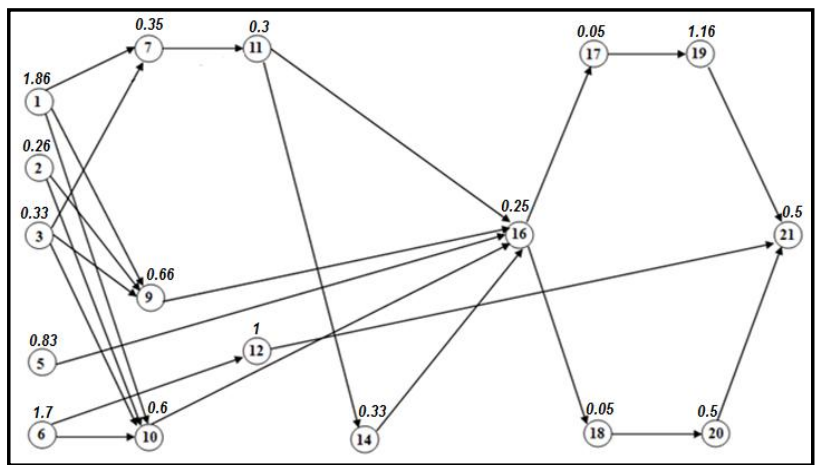

Figure 4: Precedence diagram of model B

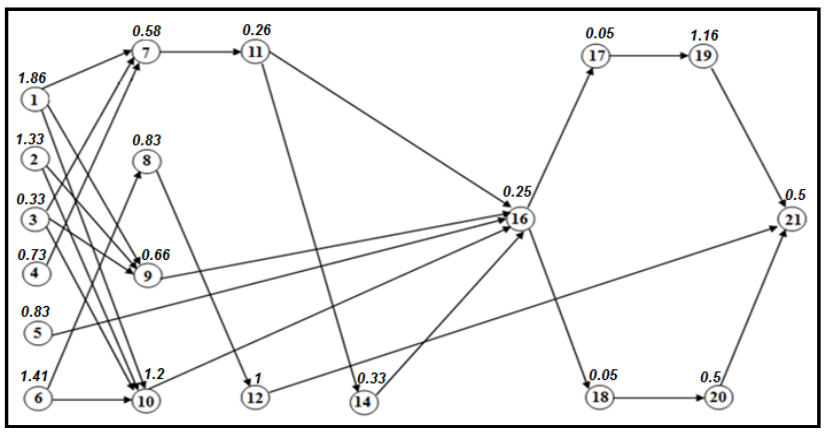

Figure 5: Precedence diagram of model C

The demand required by the customer for each model has been recorded which is ( 2 of A), (7 of B) and (13 of C) every 2 hours (120 min. which is the required available time (RAT)) for this line that has (6) fixed stations and one 
worker for each station. All the models are combined into single model called (combined model) using the following equation:

$\mathrm{TT}_{\mathrm{j}}=\sum_{\mathrm{i}=1}^{\mathrm{p}} \mathrm{R}_{\mathrm{i}} \mathrm{t}_{\mathrm{ij}}$

Where; $\mathrm{j}=1,2 \ldots \mathrm{k}$ (represent the task number)

$R i=$ the quantity demand of model $\mathrm{i}$

$t i j=$ time to perform task $\mathrm{j}$ for model $\mathrm{i}$ (min),

$\mathrm{p}=$ the number of models to be produced during the period: and $i$ is used to identify the model, $i=1,2 \ldots \ldots$.

$\mathrm{TT}_{\mathrm{j}}$ : represents the total time required for task $\mathrm{j}$ to accomplish all models that represents the time of the combined model which is showed in figure 6 .

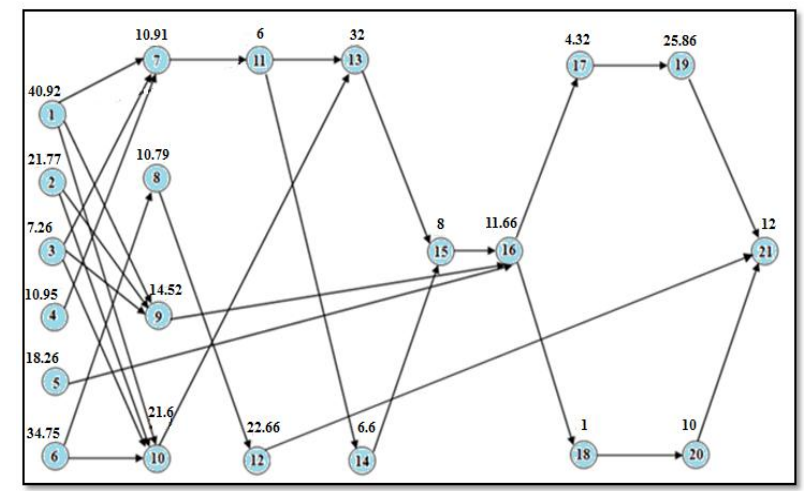

Figure 6: Precedence diagram of combined model

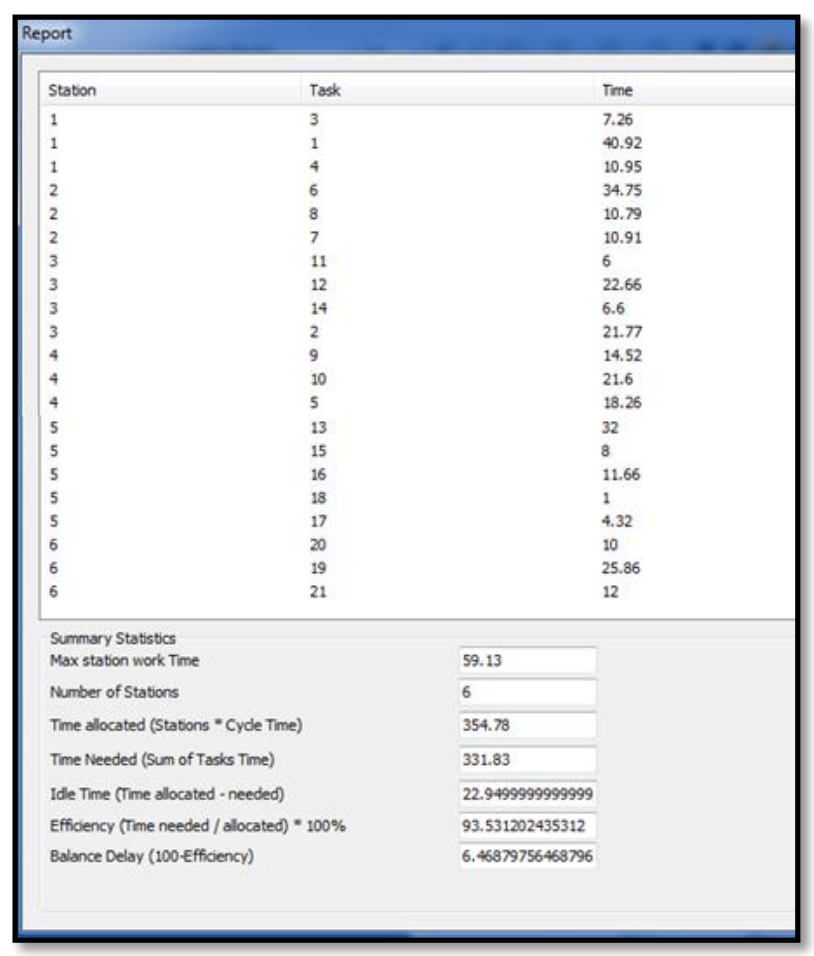

Figure 7: Report of result screen for balancing $(\mathrm{ACH})$ assembly line using (MMLSO) program

The automatic changeover $(\mathrm{ACH})$ models assembly line balanced using a heuristic method that programmed using C\# language, this program called "Assembly line balancing-Method of Merging Shortest and Longest Operation" symbol by (MMSLO) that is merging of (shortest operation time) and (longest operation time) methods. The balancing method began with theoretical minimum time $\left(\mathrm{T}_{\min }\right)$

$\mathrm{T}_{\min }=\max \left[\frac{1}{\mathrm{n}} \sum_{\mathrm{j}=1}^{\mathrm{L}} \mathrm{TT}_{\mathrm{j}}, \max \mathrm{TT}_{\mathrm{j}}\right]$

Where; $\mathrm{n}=$ represent the number of stations.

The theoretical minimum time in this line is $(55 \mathrm{~min})$ and it is increased until reach to the fixed number of station that is achieved with $(60 \mathrm{~min})$ theoretical minimum time which is called (actual time) cause it obtained the fixed number of station (6) and it is represent the allowed work time at the station. Figure 7 shows the distributing of tasks among the station in the line and the quality measures of the balancing method using (MMSLO) program that shows the max. Station work time or (cycle time) equal $59.13 \mathrm{~min}$ which is the first station.

\section{IMPLEMENTATION OF SEQUENCING PROCEDURE ON (ACH) MODELS ASSEMBLY LINE}

The method that is used for sequencing the line is goal chasing 1 . Firstly, calculate the service time $\left(\mathrm{T}_{\mathrm{sm}}\right)$ at each station for one item of each model as shown in table I, then calculate the work time at each station as shown in table II and these data can be presented in figure 8 that shows the total time of every station and the total service time of each model for every station.

TABLE I: Service Time of Each Model Unit at Each Station

\begin{tabular}{|c|c|c|c|}
\hline Station & A & B & C \\
\hline $\mathbf{l}$ & 2.92 & 2.19 & 2.92 \\
\hline $\mathbf{2}$ & 2.72 & 2.05 & 2.82 \\
\hline $\mathbf{3}$ & 2.92 & 1.89 & 2.92 \\
\hline $\mathbf{4}$ & 2.39 & 2.09 & 2.69 \\
\hline $\mathbf{5}$ & 24.99 & .35 & .35 \\
\hline $\mathbf{6}$ & 2.33 & 2.16 & 2.16 \\
\hline
\end{tabular}

TABLE II: Station Work Time

\begin{tabular}{|c|c|}
\hline Station & Station work time \\
\hline $\mathbf{1}$ & 59.13 \\
\hline $\mathbf{2}$ & 56.45 \\
\hline $\mathbf{3}$ & 57.03 \\
\hline $\mathbf{4}$ & 54.38 \\
\hline $\mathbf{5}$ & 56.98 \\
\hline $\mathbf{6}$ & 47.86 \\
\hline
\end{tabular}

Then applying equation (1-3) for all models and selecting the model that minimizes this equation until the 22 units to be launched.

Therefore, for $1=1$.

Model A

$\left(1 . \frac{\mathbf{5 9 . 1 3}}{\mathbf{2 2}}-0-2.92\right)^{2}+\left(1 . \frac{\mathbf{5 6 . 4 5}}{\mathbf{2 2}}-0-2.72\right)^{2}+\left(1 . \frac{\mathbf{5 7 . 0 3}}{\mathbf{2 2}}-0-\right.$

$2.92)^{2}+\left(1 . \frac{\mathbf{5 4 . 3 8}}{\mathbf{2 2}}-0-2.39\right)^{2}+\left(1 . \frac{\mathbf{5 6 . 9 8}}{\mathbf{2 2}}-0-24.99\right)^{2}+$

$\left(1 . \frac{47.86}{22}-0-2.33\right)^{2}=501.966$ 


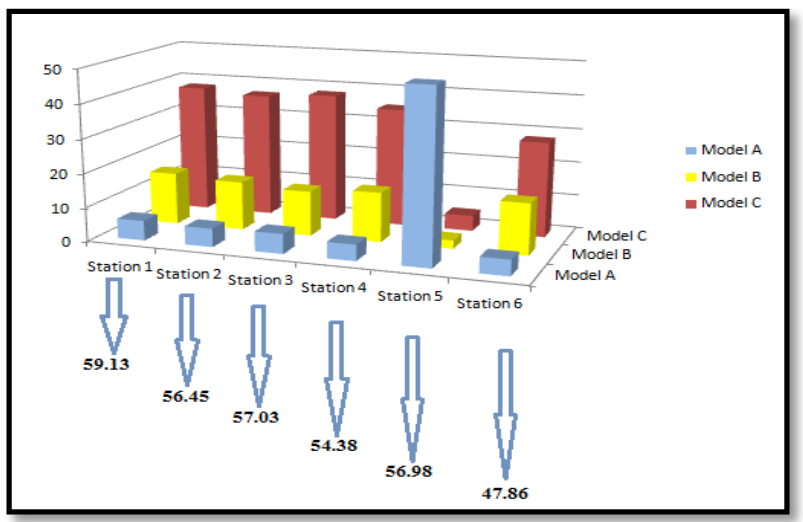

Figure 8: Models time at each station and the station work time

\section{Model B}

$\left(1 . \frac{\mathbf{5 9 . 1 3}}{\mathbf{2 2}}-0-2.19\right)^{2}+\left(1 . \frac{\mathbf{5 6 . 4 5}}{\mathbf{2 2}}-0-2.05\right)^{2}+\left(1 . \frac{\mathbf{5 7 . 0 3}}{\mathbf{2 2}}-0-\right.$

$1.89)^{2}+\left(1 . \frac{\mathbf{5 4 . 3 8}}{\mathbf{2 2}}-0-2.09\right)^{2}+\left(1 . \frac{\mathbf{5 6 . 9 8}}{\mathbf{2 2}}-0-.35\right)^{2}+$ $\left(1 . \frac{47.86}{22}-0-2.16\right)^{2}=6.170$

\section{Model C}

$\left(1 . \frac{\mathbf{5 9 . 1 3}}{\mathbf{2 2}}-0-2.92\right)^{2}+\left(1 . \frac{\mathbf{5 6 . 4 5}}{\mathbf{2 2}}-0-2.82\right)^{2}+\left(1 . \frac{\mathbf{5 7 . 0 3}}{\mathbf{2 2}}-0-\right.$ $2.92)^{2}+\left(1 . \frac{\mathbf{5 4 . 3 8}}{\mathbf{2 2}}-0-2.69\right)^{2}+\left(1 . \frac{\mathbf{5 6 . 9 8}}{\mathbf{2 2}}-0-.35\right)^{2}+$ $\left(1 . \frac{\mathbf{4 7 . 8 6}}{\mathbf{2 2}}-0-2.16\right)^{2}=\mathbf{5 . 2 9}$

Therefore the model which minimizes equation (1-3) is model $\mathrm{C}$. The computation of $\mathrm{X}_{\mathrm{i}, 1}$ has given the following results: $X_{1,1}=2.92, X_{2,1}=2.82, X_{3,1}=2.92, X_{4,1}=2.69$, $\mathrm{X}_{5,1}=.35, \mathrm{X}_{6,1}=2.16$

For the 2nd launch $(1=2)$ equation (1-3) is calculated again for each model until launching all models unit as it is shown in table III.

TABLE III: Sequencing Results for (22) Units of Three Models of $(\mathrm{ACH})$

\begin{tabular}{|c|c|c|c|c|c|c|c|}
\hline$l$ & $X_{1, l}$ & $X_{2, l}$ & $X_{3, l}$ & $X_{4, l}$ & $X_{5, l}$ & $X_{6, l}$ & Model \\
\hline 1 & 0 & 0 & 0 & 0 & 0 & 0 & $C$ \\
\hline 2 & 2.92 & 2.82 & 2.92 & 2.69 & .35 & 2.16 & $B$ \\
\hline 3 & 5.11 & 4.87 & 4.81 & 4.78 & .7 & 4.32 & $C$ \\
\hline 4 & 8.03 & 7.69 & 7.73 & 7.47 & 1.05 & 6.48 & $C$ \\
\hline 5 & 10.95 & 10.51 & 10.65 & 10.16 & 1.4 & 8.64 & $B$ \\
\hline 6 & 13.14 & 12.56 & 12.54 & 12.25 & 1.75 & 10.8 & $A$ \\
\hline 7 & 16.06 & 15.28 & 15.46 & 14.64 & 26.74 & 13.13 & $C$ \\
\hline 8 & 18.98 & 18.1 & 18.38 & 17.33 & 27.09 & 15.29 & $B$ \\
\hline 9 & 21.17 & 20.15 & 20.27 & 19.42 & 27.44 & 17.45 & $C$ \\
\hline 10 & 24.09 & 22.97 & 23.19 & 22.11 & 27.79 & 19.61 & $C$ \\
\hline 11 & 27.01 & 25.79 & 26.11 & 24.8 & 28.14 & 21.77 & $C$ \\
\hline 12 & 29.93 & 28.61 & 29.03 & 27.49 & 28.49 & 23.93 & $B$ \\
\hline 13 & 32.12 & 30.66 & 30.92 & 29.58 & 28.84 & 26.09 & $C$ \\
\hline 14 & 35.04 & 33.48 & 33.84 & 32.27 & 29.19 & 28.25 & $C$ \\
\hline 15 & 37.96 & 36.3 & 36.76 & 34.96 & 29.54 & 30.41 & $B$ \\
\hline 16 & 40.15 & 38.35 & 38.65 & 37.05 & 29.89 & 32.57 & $C$ \\
\hline 17 & 43.07 & 41.17 & 41.57 & 39.74 & 30.24 & 34.73 & $A$ \\
\hline 18 & 45.99 & 43.89 & 44.49 & 42.13 & 55.23 & 37.06 & $B$ \\
\hline 19 & 48.18 & 45.94 & 46.38 & 44.22 & 55.58 & 39.22 & $C$ \\
\hline 20 & 51.1 & 48.76 & 49.3 & 46.91 & 55.93 & 41.38 & $C$ \\
\hline 21 & 54.02 & 51.58 & 52.22 & 49.6 & 56.28 & 43.54 & $B$ \\
\hline 22 & 56.21 & 53.63 & 54.11 & 51.69 & 56.63 & 45.7 & $C$ \\
\hline
\end{tabular}

\section{SCHEDULING THE MODELS}

The scheduling section comes after getting the result of sequencing. The scheduling is the fact of recording the input and output time of every piece in the production for all stations and it records the total station time, which contains both work time and the idle time accurse between the pieces because of the variability of time between models. The manual mixed-model line of $(\mathrm{ACH})$ models has a manual transfer system. The following table presents the input and output time of each unit for every station.

TABLE IV: Scheduling Input and Output Time of Each Model Unit for Stations

\begin{tabular}{|c|c|c|c|c|c|c|c|c|c|c|c|c|}
\hline & \multicolumn{2}{|c|}{1} & \multicolumn{2}{|c|}{2} & \multicolumn{2}{|c|}{3} & \multicolumn{2}{|c|}{4} & \multicolumn{2}{|c|}{5} & \multicolumn{2}{|c|}{6} \\
\hline & $\overline{\ln }$ & Out & $\overline{I n}$ & $\overline{O_{u t}}$ & $\begin{array}{ll}\ln \\
\end{array}$ & $\delta_{u t}$ & $\operatorname{In}$ & $\overline{\text { Out }}$ & $\overline{I n}$ & Out & $\ln$ & $O_{\text {ut }}$ \\
\hline c & 0 & 2.92 & 2.92 & 5.74 & 5.74 & 8.66 & 8.66 & 11.35 & 112.35 & 11.7 & 11.7 & 17.86 \\
\hline B & 2.92 & 5.11 & 5.74 & 7.79 & 8.66 & 10.55 & 11.35 & 13,44 & 13.44 & 13.79 & 13.86 & 16.02 \\
\hline$c$ & 5.11 & 8.03 & 803 & 10.85 & 10.85 & 13.77 & 13,77 & 16.46 & 16.46 & 16.81 & 16.81 & 18.97 \\
\hline c & 8.03 & 10.95 & 10.95 & 13.77 & 13,77 & 16.69 & 16.69 & 19.38 & 19.38 & 19.73 & 19.73 & 21.89 \\
\hline$B$ & 10.95 & 73.14 & 13,77 & 15.82 & 16.69 & 18.58 & 19.38 & 21.57 & $21 ., 7$ & 21.82 & 21.89 & 24.05 \\
\hline$A$ & 13.14 & 16.06 & 16.06 & 18.78 & 18.78 & 21.7 & 21.7 & 24.09 & 24.09 & 49.08 & 99.08 & 51.41 \\
\hline C & 16.06 & 18.98 & 18.98 & 21.8 & 21.8 & 24.72 & 24.72 & 27.91 & 99.08 & 89.13 & 51.41 & 53.57 \\
\hline$B$ & 18.98 & 21.17 & 21.8 & 23.85 & 24.72 & 26.61 & 27.81 & 29.5 & 89.43 & 49.78 & 53.57 & 55.73 \\
\hline c & 21.17 & 24.09 & 24.09 & 26.91 & 2691 & 29.83 & 29.83 & 32.52 & 89.78 & 50.13 & 55.73 & 57.39 \\
\hline c & 24.09 & 27.01 & 27,01 & 29.83 & 29.83 & 32.75 & 32.75 & 35.44 & 50.13 & 50.18 & 57.89 & 60.05 \\
\hline$c$ & 27,01 & 29.93 & 29.93 & 32.75 & 32.75 & 35.67 & 33.67 & 38.36 & 50.18 & 50.83 & 60.05 & 62.21 \\
\hline$B$ & 29.93 & 32.12 & 32.75 & 34.8 & 35.67 & 37.56 & 38.36 & 80.15 & 50.83 & 51.18 & 62.21 & 66.37 \\
\hline c & 32.12 & 35.04 & 35.04 & 37.86 & 37.86 & 40.78 & $\$ 0.78$ & 83.47 & 51.18 & 51.53 & 64.37 & 66.53 \\
\hline c & 35.04 & 37.96 & 37.96 & 40.78 & 80.78 & 13.7 & 43.7 & 46.39 & 51.53 & 51.88 & 66.53 & 68.69 \\
\hline$B$ & 37.96 & 80.15 & 40.78 & 52.83 & 43,7 & 45.59 & 46.39 & 48.48 & 51.88 & 52.23 & 68.69 & 70.85 \\
\hline c & 40.15 & 83.07 & 43.07 & 45.89 & 15.89 & 48.81 & 18.81 & 51.5 & 52.23 & 52.58 & 70.85 & 73.01 \\
\hline$A$ & 83.07 & 45.99 & 45.99 & 48.71 & 48.81 & 51.73 & 51.73 & 54.12 & 54.12 & 79.11 & 79.11 & 81.44 \\
\hline$B$ & 45.99 & 18.18 & 48.71 & 50.76 & 51.73 & 53.62 & 54.12 & 56.21 & 79.11 & 79.46 & 81.44 & 83.6 \\
\hline c & 18.18 & 51.1 & 51.1 & 53.92 & 53.92 & 56.84 & 56.84 & 59.53 & 79.46 & 79.81 & 83.76 & 85.76 \\
\hline$c$ & 51.1 & 54.02 & 54.02 & 56.84 & 56.84 & 59.76 & 59.76 & 62.45 & 79.81 & 80.16 & 85.76 & 87.92 \\
\hline$B$ & 34.02 & 56.21 & 56.84 & 58.89 & 59.76 & 61.65 & 62.45 & 64.54 & 80.16 & 80.51 & 87.92 & 90.08 \\
\hline & 36.21 & 39.13 & 39.13 & 61.95 & 61.95 & 64.87 & 64.87 & 67.36 & 80.51 & 80.86 & 90.08 & 92.24 \\
\hline
\end{tabular}

From the sequencing and scheduling data above, the station work time, the idle time between units and the total time of each station can be calculated, as they are shown in table $\mathrm{V}$.

TABLE V: Work Time and Idle Time for Each Station

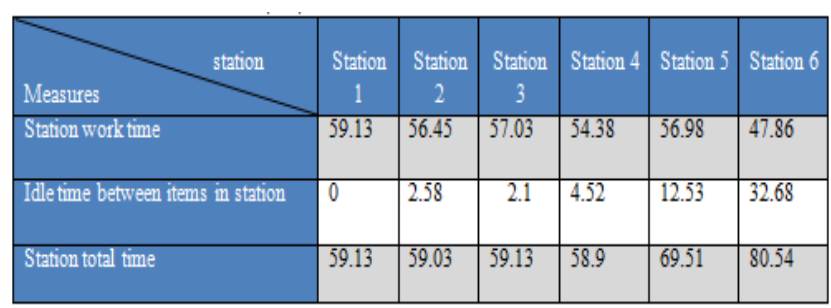

- $\quad$ Required Available Time $($ RAT $)=120$ min (specified by customer)

- $\quad$ Expected Available Time (EAT) = $92 \mathrm{~min}$ (calculated after balancing the line with shift time $=60$ ) EAT $=$ Actual TL + max. Task time at combined diagram (1-6)

$\mathrm{EAT}=60+32=92 \mathrm{~min}$ 
- $\quad$ Actual Available Time $($ AAT) $=\mathbf{8 0 . 5 4}$ min (total time of last station that calculated after sequencing and scheduling the line)

The total time of last station (AAT) $<$ (EAT) which is $(80.54<92)$ that means every 80.54 min the customer receives new batch.. Figure 9 presents the whole layout of stations and sequencing of units in the line

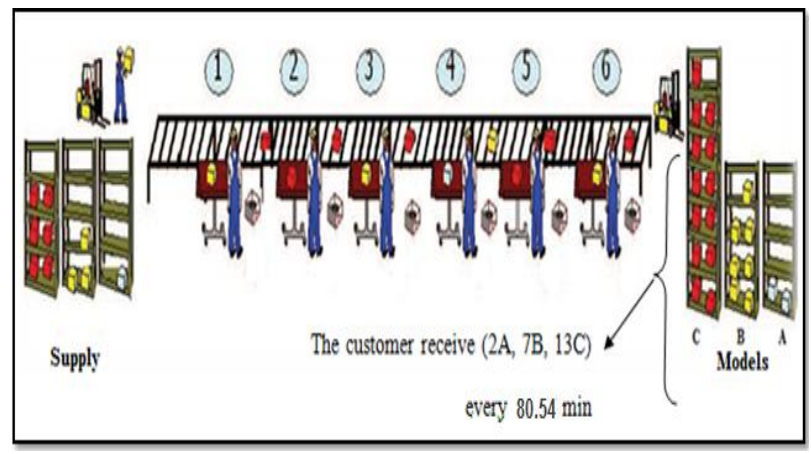

Figure 9: Arrangement of stations in the line with desired demand of models and their sequencing

\section{DISCUSSION AND EVALUATION}

the models mix of the case has been sequenced using (Goal Chasing 1) method that has generated the following sequencing of units (CBCCBACBCCCBCCBCABCCB C) that are scheduled for delivering the customer with production every $80.54 \mathrm{~min}$ (actual time) instead $92 \mathrm{~min}$ (the expected time). The remaining time implied that there is more space to increase the production rate (demand quantity).

\section{REFERENCES}

[1] F. Hellman, B. Lindahl, and J. Malmberg, "Mixed-Model Assembly Line at Volvo Construction Equipment", MSc. Thesis, Technology Management and Economics, Chalmers University oF Technology, 2011.

[2] B. Suman, and P. Kumar, "A survey of Simulated Annealing as a Tool for Single and Multiobjective Optimization", Journal of the Operational Research Society, 57, PP. 1143-1160. 2006.

[3] O". Ug ur, C. Hakan, G. Hadi, and T. Bilal, "Balancing and sequencing of parallel mixed-model assembly lines", International Journal of Production Research, Vol.48, No. 17, PP. 5089-5113, 2010.

[4] A. Noroziroshan, and S. Habibi, "A Performance Analysis of Memetic Algorithm, Genetic Algorithm and Simulated Annealing in Production System Optimization", International Journal of Soft Computing and Engineering (IJSCE), Vol.5, No. 4, PP. 2231-2307, 2015.

[5] J. Bautista, R. Alfaro-Pozo, C. Batalla-García, and A. Cano, "Solving a Mixed-Model Sequencing Problem with Production Mix Restriction by Bounded Dynamic Programming", Universitat Politècnica de Catalunya, OPE - Organizacion De La Produccion Y De Empresa, Spain, 2015.

[6] U. Ozcan, H. CercdoĞlu, H. Gokcen, and B. Toklu, "A Tabu Search Algorithm for the Parallel Assembly Line Balancing Problem", G.U. Journal of Science Vol.22, No. 4, PP. 313-323, 2009.

[7] L. Fernandes and C. J. Lâeger, "Heuristic Methods for the MixedModel Assembly Line Balancing and Sequencing", M. Eng. Thesis, Manufacturing Systems Engineering, Lehigh University. 1992.

[8] Website of Electronic Industries Company (EIC) http://www.eiciq.com/index.php?product_section=25

[9] H. Guden, "An Adaptive Simulated Annealing Method for Assembly Line Balancing and A case Study", MSc. Thesis, Industrial Engineering, Middle East Technical University, 2006.
[10] Y. Pranavi, "Productivity Improvement of A Manual Assembly Line", MSc. Thesis, Industrial Engineering, Texas A\&M University, 2011. 